\title{
C-KIT EXPRESSION IN THE SALIVARY GLAND NEOPLASMS ADENOID CYSTIC CARCINOMA, POLYMORPHOUS LOW GRADE ADENOCARCINOMA AND MONOMORPHIC ADENOMA
}

Paul C. Edwards ${ }^{1}$ M.Sc., D.D.S., T. Bhuiya ${ }^{2}$ M.D., and R. Kelsch ${ }^{3}$ D.M.D.

${ }^{1}$ Department of Dental Medicine, Division of Oral Pathology, Long Island Jewish Medical Center, New Hyde Park, NY,

${ }^{2}$ Head, Division of Surgical Pathology, Department of Pathology, Long Island Jewish Medical Center, New Hyde Park, NY, and

${ }^{3}$ Head, Section of Clinical Oral Pathology, Division of Oral Pathology, Department of Dental Medicine, Long Island Jewish Medical Center, New Hyde Park, NY.

Author's accepted manuscript; final version published as:

Edwards PC, Bhuiya T, Kelsch RD. C-kit expression in the salivary gland neoplasms adenoid cystic carcinoma, polymorphous low-grade adenocarcinoma, and monomorphic adenoma. Oral Surg Oral Med Oral Pathol Oral Radiol Endod. 2003 May;95(5):586-93. 


\section{C-KIT EXPRESSION IN THE SALIVARY GLAND NEOPLASMS ADENOID CYSTIC CARCINOMA, POLYMORPHOUS LOW GRADE ADENOCARCINOMA AND MONOMORPHIC ADENOMA}

Author's accepted manuscript; final version published as:

Edwards PC, Bhuiya T, Kelsch RD. C-kit expression in the salivary gland neoplasms adenoid cystic carcinoma, polymorphous low-grade adenocarcinoma, and monomorphic adenoma. Oral Surg Oral Med Oral Pathol Oral Radiol Endod. 2003 May;95(5):586-93. 
This manuscript was presented at the:

American Academy of Oral and Maxillofacial Pathology Annual Meeting, New Orleans, LA,

April 22, 2002. 


\begin{abstract}
The tyrosine kinase receptor protein c-kit exerts a broad range of activities during organogenesis and normal cell development. It is involved in the development of multiple haematopoietic cell lines, mast cells, melanogenesis, interstitial cells of Cajal and gametogenesis. Recent studies have revealed that over-expression of c-kit protein occurs in a narrow subset of malignant neoplasms, including gastrointestinal stromal tumors, myeloid leukemias, seminomas and adenoid cystic carcinomas (ACC). C-kit reportedly is not expressed in polymorphous low-grade adenocarcinoma (PLGA).
\end{abstract}

We examined the expression of the c-kit antigen in the malignant salivary gland neoplasms ACC and PLGA and compared it to its expression in the benign salivary gland tumor monomorphic adenoma (including trabecular adenoma, canalicular adenoma and basal cell adenoma).

Formalin-fixed paraffin-embedded sections of 49 salivary gland neoplasms (17 monomorphic adenomas, 17 PLGA and 15 ACC) accessioned between 1989 and 2002 were retrieved from the files of the Department of Pathology, Long Island Jewish Medical Center, New Hyde Park, NY, and were stained with an anti-c-kit polyclonal antibody.

C-kit reactivity was uniformly positive in the cytoplasm of luminal neoplastic cells in ACCs $(15 / 15,100 \%)$. Positive reactivity was also identified in the majority of PLGAs $(16 / 17,94 \%)$, with at least $25 \%$ of the tumor cells being positive. Similar reactivity was seen in monomorphic adenomas $(16 / 17,94 \%)$. In the normal surrounding salivary gland tissue, c-kit reactivity was identified only focally in ductal epithelium.

In contrast to previous reports, we find that c-kit expression was not restricted to ACC but was expressed in all three tumor types evaluated (ACC, PLGA and monomorphic adenoma). Therefore, c-kit does not appear to be an ideal marker for distinguishing between ACC and PLGA in equivocal cases, or benign from malignant salivary gland neoplasms. 


\section{INTRODUCTION}

The transmembrane tyrosine kinase receptor c-kit (CD117) is a 145 to $165 \mathrm{kD}$ protooncogene that is structurally related to the platelet-derived growth factor (PDGF) receptor and the colony stimulatory factor (CSF) receptor ${ }^{1}$. Binding of its ligand (alternatively known as steel factor, stem cell factor, and mast cell growth factor) promotes phosphorylation, which subsequently activates a signaling cascade that regulates cell growth and development.

C-kit is expressed in a range of normal developmental pathways, including hematopoiesis and spermatogenesis. It is required for the normal migration and development of germ cells and melanocytes ${ }^{1}$. It has been shown that mice bearing mutations in this gene locus are characterized by severe macrocytic anemia, lack of pigmentation and sterility.

In normal human tissue, c-kit is expressed in melanocytes, breast epithelium cells, mast cells $^{2}$, and the interstitial cells of $\mathrm{Cajal}^{3}$, which initiate and propagate slow muscle activity in gastrointestinal muscles.

Over-expression of this tyrosine kinase receptor has been reported in a subset of malignant neoplasms such as gastrointestinal stromal tumors (GIST) ${ }^{4}$, myeloid leukemia, testicular germ cell tumors ${ }^{5}$, endometrial carcinomas, papillary and follicular thyroid carcinomas $^{5}$, renal and hepatic angiomyolipoma ${ }^{6}$, synovial sarcoma ${ }^{7}$, osteosarcoma $^{7}$ and Ewing's sarcoma ${ }^{7}$.

In human salivary gland neoplasms, reports of c-kit expression have been contradictory. Several reports have suggested that c-kit is expressed in ACC. It is reportedly absent in PLGA $^{1,8,9}$. Based on these findings, it has been suggested that c-kit expression may be a suitable immunohistochemical marker to aid in distinguishing between these two neoplasms.

The purpose of this study was to compare the extent of c-kit immunoreactivity in adenoid cystic carcinoma, polymorphous low-grade adenocarcinoma and monomorphic adenoma. 


\section{MATERIALS AND METHODS}

Formalin-fixed paraffin-embedded sections of 49 salivary gland neoplasms (17 monomorphic adenomas, 17 PLGA and 15 ACC) accessioned between 1989 and 2002 were retrieved from the files of the Department of Pathology, Long Island Jewish Medical Center.

The H\&E stained slides were independently reviewed by three experienced pathologists (RK, JF, TB) and agreement was reached on all cases included in this study using accepted criteria ${ }^{10}$.

Microwave heat-induced epitope retrieval $(750 \mathrm{~W}$ microwave at medium power, 30 minutes) was performed using the Trilogy ${ }^{\mathrm{TM}}$ system (Cell Marque, Hot Springs AK) as per the manufacturer's directions and then treated with anti-human c-kit polyclonal antibody (Dako, Kyoto, Japan) at a 1:100 dilution.

The antibody-antigen complex was detected using an indirect biotin-avidin system as per the manufacturer's instructions (Ventana Basic DAB Detection Kit ${ }^{\mathrm{TM}}$, Ventana Medical Systems, Tucson AZ).

Large cell undifferentiated lung carcinoma was used as positive controls for the c-kit marker. Normal salivary gland tissue was used as the negative control.

Immunoreactivity was independently assessed by all study participants. Agreement was reached on all 49 specimens examined. Immunoreactivity was considered positive if greater than $10 \%$ of the tumor cells stained and was graded as weak (10-25\%), mild (26$50 \%)$, moderate $(51-75 \%)$ and strong (76-100\%). 


\section{RESULTS}

The ACC group, comprising 12 women and 3 men, had a median age of 65 years (range: 37-89 years). The tumor group included 8 lesions of minor salivary gland origin (4 palate, 3 soft tissue of the neck, 1 maxillary sinus) and 7 lesions of major gland origin (5 parotid, 2 submandibular gland).

The median age of the PLGA group was 67 years (range: $38-73$ years) and consisted of 13 female patients and 4 male patients. All tumors arose from minor salivary gland tissue, primarily palate (8) and buccal mucosa (4), except for one of parotid origin.

The monomorphic adenoma group, comprising 14 women and 3 men, had median age of 66 years (range: 41-97). The tumors were located in the upper lip (9), parotid (4), buccal mucosa (3), and hard palate (1).

C-kit expression (Table 1) was evident in 15/15 ACCs as indicated by positive immunoreactivity. Cytoplasmic staining was identified in the luminal neoplastic cells in ACC (Fig.1). C-kit expression was more prominent in solid variants of ACC. The intensity of staining was strongest in ACCs of minor salivary gland origin (Table 2).

Positive reactivity was also noted in the majority of PLGAs $(16 / 17,94 \%)$ with at least $25 \%$ of the tumor cells being positive (Table 1, Fig.2). However, there was variable immunoreactivity, ranging from faint focal to strong positivity. The overall intensity of staining was weaker in PLGA as compared to ACC.

Similar positive immunoreactivity $(16 / 17,94 \%)$ was identified in monomorphic adenomas (Table 1, Fig.3). Expression was primarily noted in the luminal cells as in $\mathrm{ACC}$, but the overall intensity was weaker than in ACC.

In the normal surrounding salivary gland tissue, c-kit reactivity was focally detected in the ductal epithelium. 


\section{DISCUSSION}

Overlapping features of infiltrating tubular and solid growth patterns combined with a tendency for perineural invasion can make the light microscopic distinction between PLGA and ACC challenging. In addition, canalicular and basal cell adenomas (monomorphic adenomas) can bear a striking resemblance to ACC, especially when examining tissue obtained from small or fragmented incisional biopsies.

This study attempts to identify a highly specific immunohistochemical marker to distinguish between these entities, which to date has proven elusive.

\section{C-Kit Expression in ACC, PLGA and Monomorphic Adenoma}

In this study, the results showed that c-kit expression was not restricted to ACC but was significantly expressed in all three tumor types evaluated.

Our finding that c-kit expression is positive in all ACCs examined is in agreement with previously published results ${ }^{11,12}$, which reported that c-kit expression is highly positive in ACC, particularly solid variants ${ }^{13,14}$.

The intensity of staining is also of interest. In our study, strong staining ( $>75 \%$ of neoplastic cells) was identified in $43 \%$ of ACCs of major salivary gland origin compared with $100 \%$ of ACCs of minor salivary gland origin. In contrast, Oprea et $\mathrm{al}^{15}$ reported that expression was lower in ACC arising in minor salivary glands as opposed to major salivary gland ACCs, whereas Holst ${ }^{14}$ found no difference. Since c-kit reactivity is strongest in solid variants of ACC, variations in the predominant subtypes of ACC in different studies could account for these differences. In our study, there was a predominance of solid variant ACC in the minor salivary gland subgroup.

Published reports of c-kit immunohistochemical reactivity in ACC have been contradictory.

In an abstract comparing staining between ACC and PLGA, Penner et $\mathrm{al}^{8}$ reported cytoplasmic c-kit expression in 6 of 6 ACCs from major and minor salivary glands, but only 1 of 3 polymorphous low-grade adenocarcinomas (PLGAs). In a subsequent manuscript ${ }^{9}$, they identified weak c-kit immunoreactivity in 8/14 (57\%) PLGAs. The intensity of c-kit staining was reportedly much stronger in ACC as compared to PLGA. Jeng et $\mathrm{al}^{1}$ found moderate to strong c-kit expression in ACC (3/4 tubular ACC, 8/17 cribriform ACC and 4/4 solid ACC), but no expression in PLGA (0/4). In contrast, our results concur with the findings of Cohn et $\mathrm{al}^{16}$. They reported that ACC $(8 / 8)$ and PLGA (7/8) demonstrated similar immunostaining patterns, with strong immunoreactivity in both neoplasms.

The contradictory and disparate c-kit immunostaining results seen in PLGA are similar to the often divergent results reported between different studies of c-kit expression in soft tissue tumors ${ }^{17}$. These differences are likely due in part to the limited number of cases examined in individual reports and to variations in the experimental protocols and 
antibodies employed. Hornick and Fletcher ${ }^{17}$ concluded that variations in immunohistochemical technique could lead to major discrepancies in positive staining.

Jeng et $\mathrm{al}^{1}$ employed a pressure cooker for epitope retrieval and used a different polyclonal anti-c-kit antibody (Medical and Biological Laboratories, Nagoya, Japan) than was used in this study (Dako, Kyoto, Japan). The Dako anti-c-kit antibody, used at a dilution of 1:100 in this study, reportedly has low background staining and is the antibody specified in the multi-center trial of Gleevec chemotherapy in GIST ${ }^{17}$. Penner et $\mathrm{al}^{9}$ also used the Dako antibody, but at a lower concentration (1:200) and with a pressure cooker for epitope retrieval.

No published studies to date have compared expression of c-kit in ACC or PLGA to the benign salivary gland neoplasm monomorphic adenoma. In our present study, we found no evidence of differences in c-kit staining between these neoplasms.

\section{Selective Immunohistochemical Markers in ACC, PLGA and Monomorphic Adenoma} Other immunohistochemical markers have been reported to be of possible benefit in distinguishing between ACC, PLGA and monomorphic adenoma.

It has been reported ${ }^{18}$ that $\mathrm{S}-100$ immunoreactivity may be of value in differentiating ACC from PLGA. Although S-100 is positive in both neoplasms, staining is reportedly more diffuse and stronger in PLGA as compared to ACC. Strong S-100 and weak actin staining of PLGA compared to weak S-100 and moderate actin staining of ACC may aid in separating these two entities ${ }^{18}$.

Araujo et $\mathrm{al}^{19}$, comparing cribriform areas of PLGA and ACC, reported that in contrast to ACC, the neoplastic luminal cells in cribriform areas of PLGA were positive for cytokeratin and integrin markers.

Skalova et $\mathrm{al}^{20}$ reported a higher MIB1 (Ki-67 nuclear proliferation marker) index, in ACCs (21.4\%) as compared to PLGAs (2.4\%). The combination of MIB1, S-100 and Bcl-2 reportedly ${ }^{21}$ allows differentiation of ACC from PLGA.

Prasad et $\mathrm{al}^{22}$ compared the immunoreactivity of ACC, PLGA and canalicular adenomas with the monoclonal antibodies $\alpha$-smooth muscle actin, smooth muscle myosin heavy chain and calponin and concluded that the consistently positive staining pattern in ACCs may be diagnostically useful in discriminating histologically similar but consistently negative PLGAs and canalicular adenomas. A separate study ${ }^{23}$ reported that the antimuscle actin antibody HHF35 stained tubular and cribriform patterns of ACC, but solid variants of ACC.

Glial fibrillary acidic protein (GFAP) is an intermediate filament cytoplasmic protein found in normal and neoplastic glial cells. Curran et al ${ }^{24}$ concluded that although not all monomorphic adenomas are positive for GFAP, the presence of GFAP reactivity at the tumor/connective tissue interface is specific for monomorphic adenoma. 
GFAP does not appear to be of value in discriminating between ACC and PLGA ${ }^{25}$, since both of these neoplasms tend to be consistently negative for c-kit immunoreactivity ${ }^{26}$. 


\section{CONCLUSION}

C-kit reactivity was uniformly positive in the cytoplasm of luminal neoplastic cells in all ACCs examined. Positive reactivity was also identified in the majority of PLGAs and monomorphic adenomas. In the normal surrounding salivary gland tissue, c-kit reactivity was identified only focally in ductal epithelium.

Of potential therapeutic interest is the recent observation that the tyrosine kinase inhibitor Gleevec (Imatinib mesylate, formerly STI571, Novartis Pharmaceuticals, Switzerland) appears to be effective in the treatment of gastrointestinal stromal tumors ${ }^{27}$. Gleevec inhibits the kinase activity of the normal c-Abl gene product, the oncogenic Bcr-Abl fusion protein involved in the pathogenesis of chronic myeloid leukemia, the plateletderived growth factor receptor as well as ligand-independent c-kit phosphorylation ${ }^{28}$.

Whether Gleevec will prove effective as an adjunct in treating ACCs, which generally have a very poor long-term prognosis, remains to be determined. Unlike gastrointestinal stromal tumors, in which c-kit gain-of-function mutations of the juxtamembrane domain of exon 11 are noted, and mast cell tumors, in which mutations in the tyrosine kinase domain of exon 17 have been identified, both Holst et $\mathrm{al}^{14}$ and Jeng et al ${ }^{1}$ failed to identify similar mutations in c-kit positive salivary gland neoplasms examined. This might argue against a potential therapeutic benefit from Gleevec-based chemotherapy.

In summary, we find that in contrast to previous reports, c-kit expression was not restricted to ACC but was expressed in all three tumor types evaluated (ACC, PLGA and monomorphic adenoma). Therefore, c-kit does not appear to be an ideal marker for distinguishing between ACC and PLGA in equivocal cases, or benign from malignant salivary gland neoplasms. These markers lack the specificity required to be of routine use in daily pathology practice. 


\begin{tabular}{|l|c|c|c|}
\hline & $\begin{array}{l}\text { ADENOID CYSTIC } \\
\text { CARCINOMA }\end{array}$ & $\begin{array}{l}\text { POLYMORPHOUS LOW } \\
\text { GRADE } \\
\text { ADENOCARCINOMA }\end{array}$ & $\begin{array}{l}\text { MONOMORPHIC } \\
\text { ADENOMA }\end{array}$ \\
\hline $\begin{array}{l}\text { Total number of } \\
\text { samples }\end{array}$ & 15 & 17 & 17 \\
\hline Negative staining & 0 & 1 & 1 \\
\hline $\begin{array}{l}\text { Weak staining } \\
(10-25 \% \text { of cells) }\end{array}$ & 0 & 4 & 1 \\
\hline $\begin{array}{l}\text { Mild staining } \\
(26-50 \%)\end{array}$ & 1 & 3 & 10 \\
\hline $\begin{array}{l}\text { Moderate staining } \\
(51-75 \%)\end{array}$ & 3 & 5 & $\mathbf{9 4 \%}$ \\
\hline $\begin{array}{l}\text { Strong staining } \\
(76-100 \%)\end{array}$ & 11 & $\mathbf{9 4 \%}$ & 4 \\
\hline $\begin{array}{l}\text { \% samples with } \\
\text { positive staining }\end{array}$ & $\mathbf{1 0 0 \%}$ & & 17 \\
\hline
\end{tabular}

\section{Table 1: Summary of c-kit staining results}




\begin{tabular}{|l|c|c|}
\hline & $\begin{array}{l}\text { MAJOR } \\
\text { SALIVARY } \\
\text { GLAND ORIGIN }\end{array}$ & $\begin{array}{l}\text { MINOR SALIVARY } \\
\text { GLAND ORIGIN }\end{array}$ \\
\hline $\begin{array}{l}\text { Total number of } \\
\text { samples }\end{array}$ & 7 & 8 \\
\hline Negative staining & 0 & 0 \\
\hline $\begin{array}{l}\text { Weak staining } \\
(10-25 \% \text { of cells })\end{array}$ & 0 & 0 \\
\hline $\begin{array}{l}\text { Mild staining } \\
(26-50 \%)\end{array}$ & 1 & 0 \\
\hline $\begin{array}{l}\text { Moderate staining } \\
(51-75 \%)\end{array}$ & 3 & 8 \\
\hline $\begin{array}{l}\text { Strong staining } \\
(76-100 \%)\end{array}$ & 3 & $\mathbf{1 0 0 \%}$ \\
\hline $\begin{array}{l}\text { \% samples with } \\
>75 \% \text { staining }\end{array}$ & $\mathbf{4 3 \%}$ & \\
\hline
\end{tabular}

\section{Table 2: Summary of c-kit staining in Adenoid Cystic Carcinoma by origin: major salivary gland versus minor salivary gland origin}


Figure 1: Adenoid Cystic Carcinoma (H\&E and c-kit, 200X).

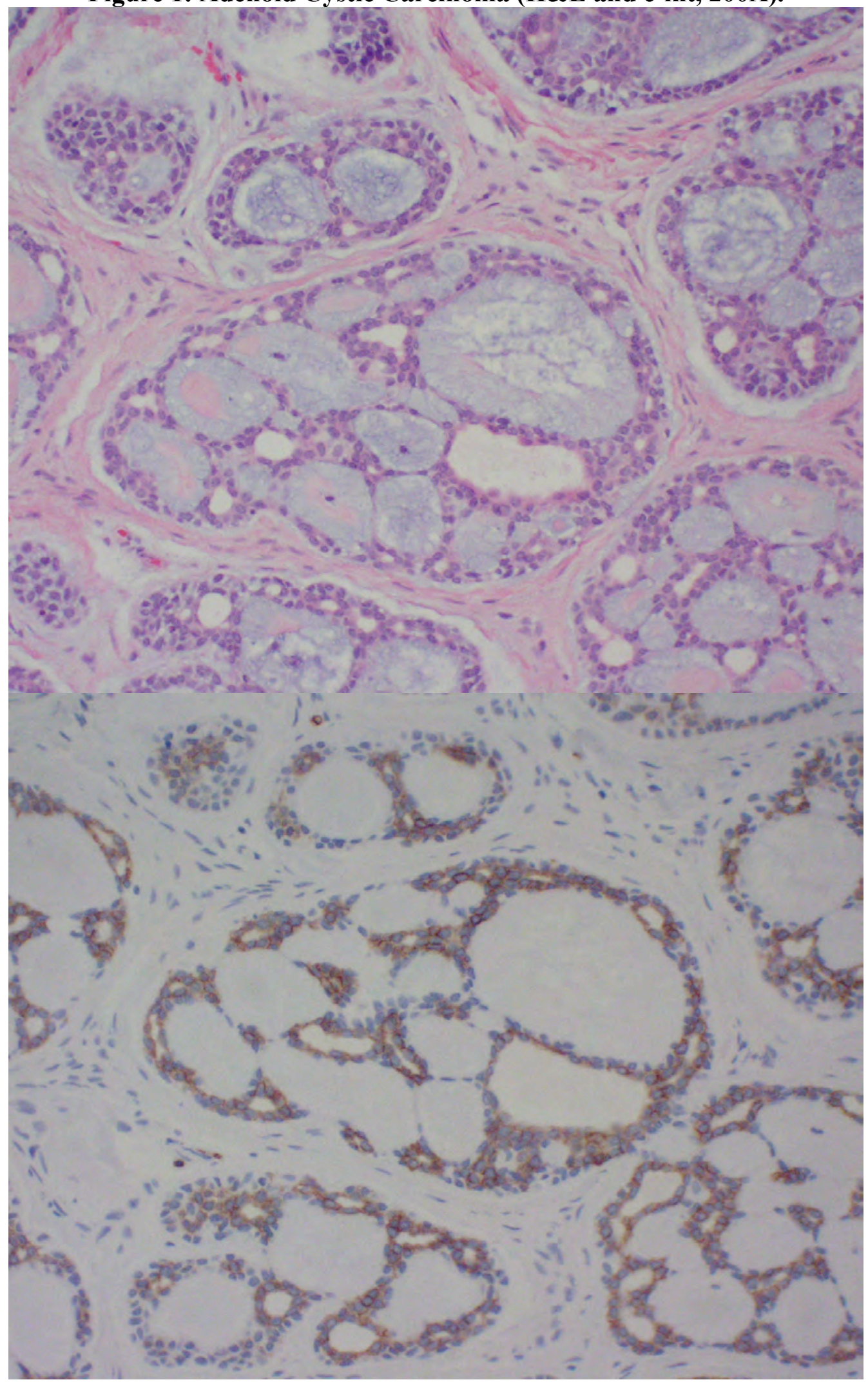


Figure 1: Adenoid Cystic Carcinoma (H\&E and c-kit, 200X). 
Figure 2: Polymorphous Low Grade Adenocarcinoma (H\&E and c-Kit, 100X)

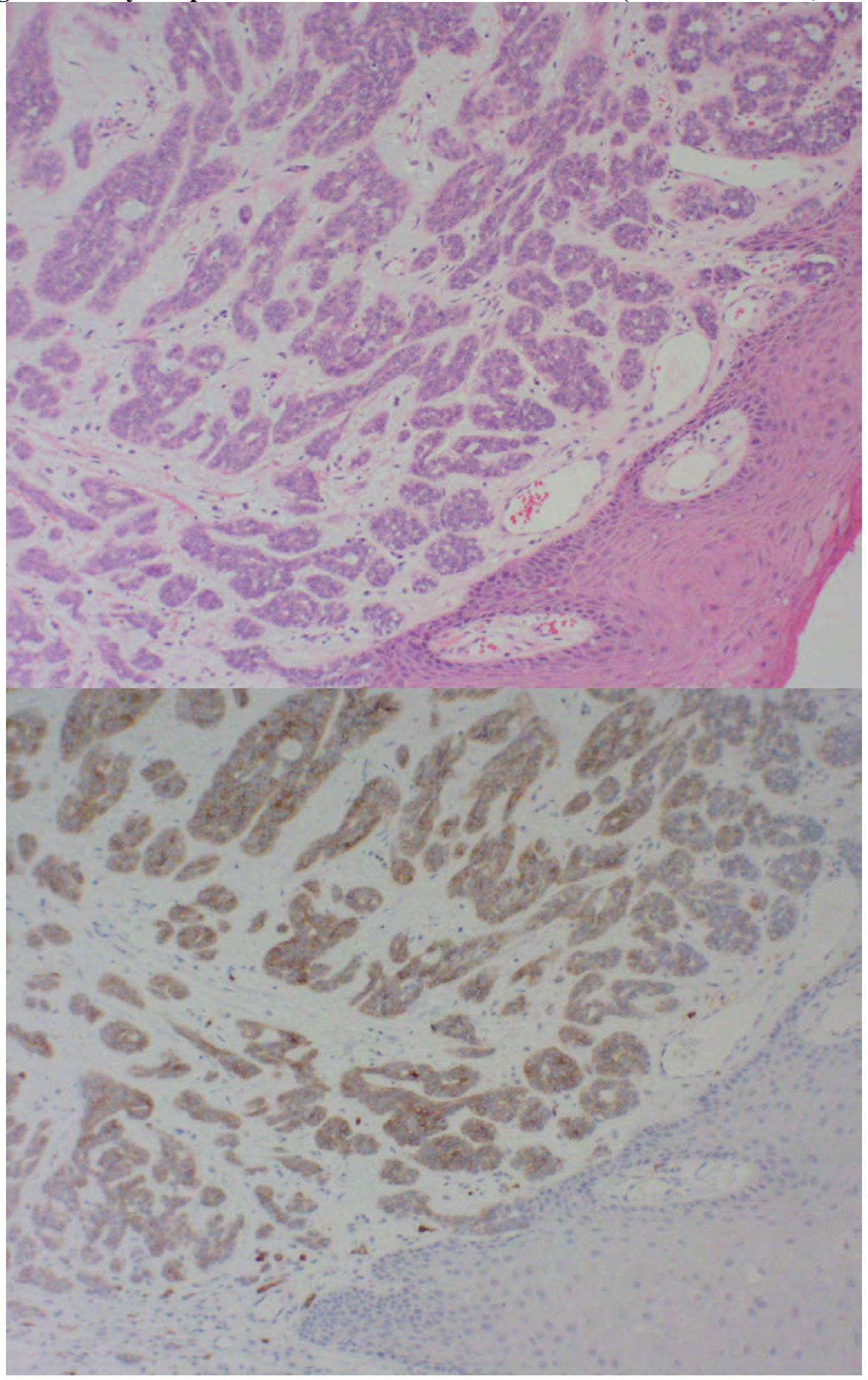


Figure 2: Polymorphous Low Grade Adenocarcinoma (H\&E and c-Kit, 100X) 
Figure 3: Monomorphic Adenoma (H\&E and c-kit, 100X).

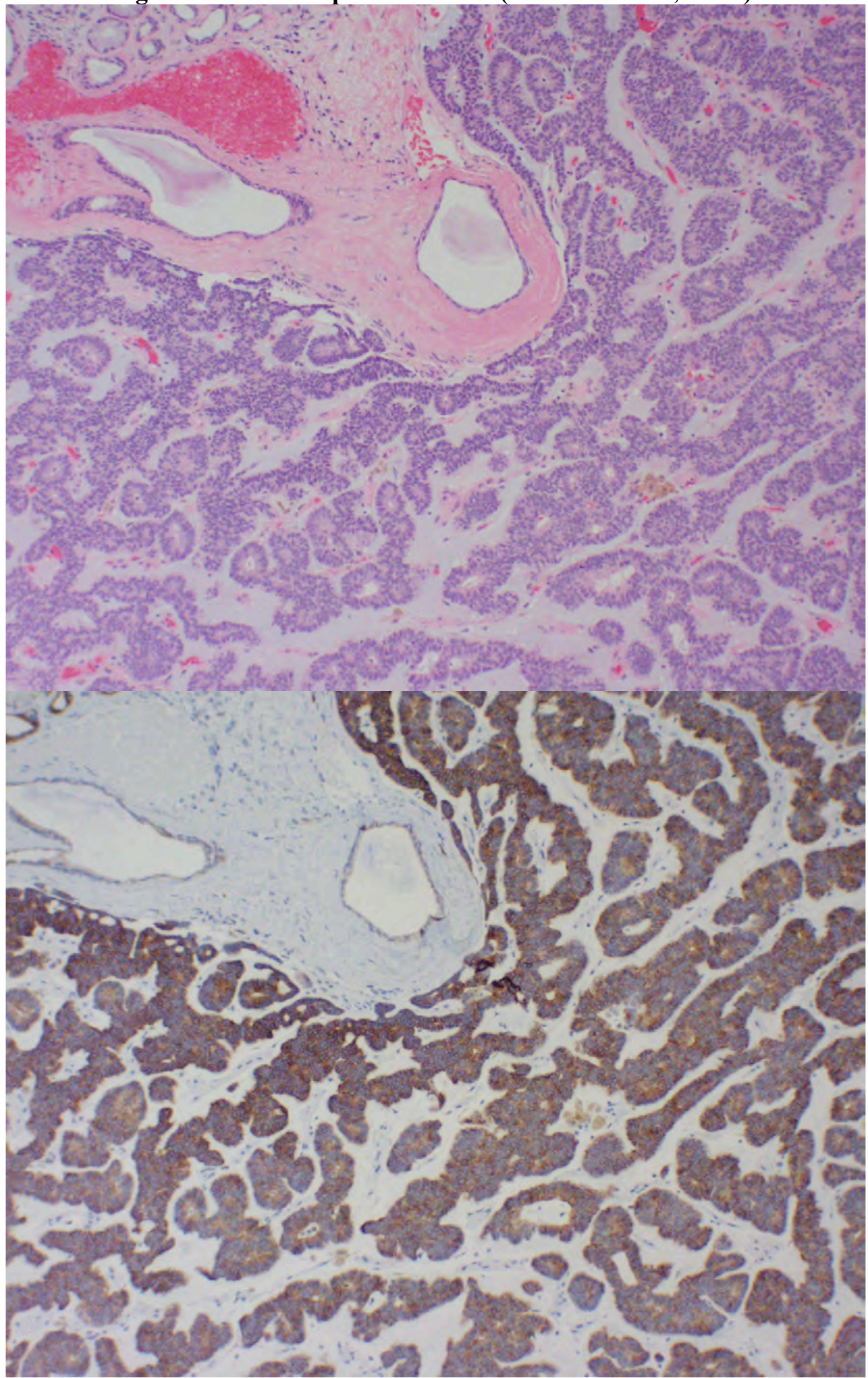


Figure 3: Monomorphic Adenoma (H\&E and c-kit, 100X). 


\section{ACKNOWLEDGEMENTS}

We would like to thank Dr. John E. Fantasia, D.D.S., Head, Division of Oral Pathology, Department of Dental Medicine, Long Island Jewish Medical Center, New Hyde Park, NY for his support and assistance in preparing this manuscript.

We also wish to thank Dr. Alexander Fuchs, M.D., Head, Division of Immunopathology, Department of Pathology, Long Island Jewish Medical Center, New Hyde Park, and Mr. Antonio Albert Tarectecan, HT (ASCP), Immuno-Analytical Technologist, Division of Immunopathology, Department of Pathology, Long Island Jewish Medical Center, New Hyde Park, for there assistance. 
${ }^{1}$ Jeng Y-M, Lin C-Y, Hsu H-C. Expression of the c-kit protein is associated with certain subtypes of salivary gland carcinoma. Cancer Letters 2000; 154: 107-111.

2 Arber DA, Tamayo R, Weiss LM. Paraffin section detection of the c-kit gene product (CD117) in human tissues: Value in the diagnosis of mast cell disorders. Human Pathol 1998; 28: 498-504.

${ }^{3}$ Andersson J, Sjogren H, Meis-Kindblom JM, Stenman G, Aman P, Kindblom L-G. The complexity of kit gene mutations and chromosome rearrangements and their clinical correlation in gastrointestinal stromal (pacemaker) tumors. Amer J Pathol 2002; 160: $15-22$.

${ }^{4}$ Graadt van Roggen JF, van Velthuysen MLF, Hogendoorn PCW. The histopathological differential diagnosis of gastrointestinal stromal tumors. J Clin Pathol 2001; 54: 96-102.

${ }^{5}$ Leroy X, Augusto D, Leteurtre E, Gosselin B. CD30 and CD117 (c-kit) used in combination are useful for distinguishing embryonal carcinoma from seminoma. $\mathrm{J}$ Histochem and Cytochem 2002; 50: 283-286.

${ }^{6}$ Makhlouf HR, Remotti HE, Ishak KG. Expression of kit (CD117) in angiomyolipoma. American J Surg Path 2002; 26: 493-497.

7 Smithey BE, Pappo AS, Hill DA. C-kit expression in pediatric solid tumors. A comparative immunohistochemical study. American J Surg Path 2002; 26: 486-492.

${ }^{8}$ Penner CR, Cox DP, Folpe AL, Budnick S. C-kit expression distinguishes adenoid cystic carcinoma (ACC) from polymorphous low-grade adenocarcinoma (PLGA). Abstract \#892: 2001 United States and Canadian Academy of Pathology Annual Meeting (New Orleans, LA).

9 Penner CR, Folpe AL, Budnick SD. C-kit expression distinguishes salivary gland adenoid cystic carcinoma from polymorphous low-grade adenocarcinoma. Modern Pathology 2002; 15: 687-691.

10 Ellis GL, Auclair PL. Tumors of the salivary gland. Atlas of tumor pathology. Third series. Fascicle 17. 1995. Armed Forces Institute of Pathology, Washington, DC.

${ }^{11}$ Mino M, Pilch BZ, Faquin WC. Expression of c-kit in adenoid cystic carcinomas, salivary gland tumors and basaloid neoplasms of the head and neck. Abstract \#930: 2002 United States and Canadian Academy of Pathology Annual Meeting (Chicago, IL).

${ }^{12}$ Liu CZ, Keelawat S, Barnes EL. Differential expression of c-kit distinguishes salivary gland adenoid cystic carcinoma (ACC) from basal cell adenocarcinoma (BCAC). Abstract \#929: 2002 United States and Canadian Academy of Pathology Annual Meeting (Chicago, IL).

${ }^{13}$ Oprea GM, Khalil Z, Mesa H, Manivel JC, Setty S, Pambuccian SE. Value of c-kit (CD117) staining in the differential diagnosis of basaloid tumors of the head and neck. Abstract \#934: 2002 United States and Canadian Academy of Pathology Annual Meeting (Chicago, IL).

${ }^{14}$ Holst VA, Marshall CE, Moskaluk CA, Frierson HF. Kit expression and analysis of ckit gene mutation in adenoid cystic carcinoma. Modern Pathology 1999; 12: 956-960.

${ }^{15}$ Oprea GM, Bachowski G, Lundeen SJ, Gulbahce HE, Coad JE, Pambuccian SE. C-kit (CD117) expression is higher in adenoid cystic carcinoma (ACC) arising in major 
salivary glands than in ACC arising in other locations. Abstract \#93: 2002 United States and Canadian Academy of Pathology Annual Meeting (Chicago, IL).

${ }^{16}$ Cohn ML, Said-Al-Naif N, Bell WC. Immunoreactivity of salivary gland tumors for CK-7, CK-20 and C-kit. Abstract \#910: 2002 United States and Canadian Academy of Pathology Annual Meeting (Chicago, IL).

17 Hornick JL, Fletcher CDM. Immunohistochemical staining for kit (CD117) in soft tissue sarcoma is very limited in distribution. Amer J Clin Pathol 2002; 117: 186-193.

${ }^{18}$ Simpson RHW, Clarke TJ, Sarsfield PTL, Gluckman PGC, Babajews AV. Polymorphous low-grade adenocarcinoma of the salivary glands: a clinicopathological comparison with adenoid cystic carcinoma. Histopathology; 1991;19: 121-129.

${ }^{19}$ Araujo VC, Loducca SVL, Sousa SOM, Williams DM, Araujo NS. The cribriform features of adenoid cystic carcinoma and polymorphous low-grade adenocarcinoma: Cytokeratin and integrin expression. Ann Diag Pathol 2001; 5: 330-334.

${ }^{20}$ Skalova A, Simpson RH, Lehtonen H, Leivo I. Assessment of proliferative activity using the MIB1 antibody to help distinguish polymorphous low grade adenocarcinoma from adenoid cystic carcinoma of salivary glands. Pathology Research and Practice 1997; 193: 695-703.

${ }^{21}$ R, Vargus H, Sudilovsky D, Kaplan MJ, Regezi JA. Mixed tumor, polymorphous lowgrade adenocarcinoma, and adenoid cystic carcinoma of the salivary gland: Pathogenic implications and differential diagnosis by Ki-67 (MIB-1), BCL2, and S-100 immunostaining. Modern Pathol 1997; 10: Abstract 117A.

${ }^{22}$ Prasad AR, Savera AT, Gown AM, Zarbo RJ. The myoepithelial immunophenotype in 135 benign and malignant salivary gland tumors other than pleomorphic adenoma. Arch Pathol Lab Med 1999; 123: 801-806.

23 Araujo VC, Carvalho YR, Araujo NS. Actin versus vimentin in myoepithelial cells of salivary gland tumors: A comparative study. Oral Surg Oral Med Oral Pathol 1994; 77 : 387-391.

${ }^{24}$ Curran A, Allen C, Beck F, Murrah V. Glial fibrillary acidic protein (GFAP) expression in basal cell and canalicular adenomas (BCA/CAN) vs. polymorphous low grade adenocarcinomas as an adjunct in diagnosis of morphologically similar cases.

Abstract \#11: 2002 American Association of Oral and Maxillofacial Pathology Annual Meeting (New Orleans, LA).

${ }^{25}$ Regezi JA, Zarbo RJ, Stewart JCB, Courtney RM. Polymorphous low-grade adenocarcinoma of minor salivary gland: a comparative histologic and immunohistochemical study. Oral Surg Oral Med Oral Pathol 1991; 71: 469-475.

${ }^{26}$ Curran AE, White DK, Damm DD, Murrah VA. Polymorphous low-grade adenocarcinoma versus pleomorphic adenoma of minor salivary glands: Resolution of a diagnostic dilemma by immunohistochemical analysis with glial fibrillary acidic protein. Oral Surg Oral Med Oral Pathol Oral Radiol Endod 2001; 91: 194-199.

27 Joensuu H, Roberts PJ, Sarlomo-Rikala M, Andersson LC, Tervahartiala P, Tuveson D, et al. Effect of the tyrosine kinase inhibitor STI571 in a patient with a metastatic gastrointestinal stromal tumor. New England J Medicine 2001; 344: 1052-1056.

${ }^{28}$ Demetri GD. Targeting c-kit mutations in solid tumors: scientific rationale and novel therapeutic options. Seminars in Oncology“ 2001; 28: 19-26. 